\title{
Exit Options in Corporate Finance: Liquidity versus Incentives
}

\section{Citation}

Aghion, P., P. Bolton, and J. Tirole. 2004. "Exit Options in Corporate Finance: Liquidity Versus Incentives." Review of Finance 8 (3) (January 1): 327-353.

\section{Published Version}

doi:10.1007/s10679-004-2542-0

\section{Permanent link}

http://nrs.harvard.edu/urn-3:HUL.InstRepos:12500289

\section{Terms of Use}

This article was downloaded from Harvard University's DASH repository, and is made available under the terms and conditions applicable to Other Posted Material, as set forth at http:// nrs.harvard.edu/urn-3:HUL.InstRepos:dash.current.terms-of-use\#LAA

\section{Share Your Story}

The Harvard community has made this article openly available.

Please share how this access benefits you. Submit a story.

\section{Accessibility}




\title{
Exit Options in Corporate Finance: Liquidity versus Incentives $^{1}$
}

\author{
Philippe Aghion \\ University College London, CEPR and EBRD \\ Patrick Bolton \\ Princeton University, CEPR and NBER \\ Jean Tirole \\ IDEI, Toulouse, CERAS, Paris and MIT
}

26 September 2000

\begin{abstract}
This paper characterizes optimal security design in the context of a corporate financing problem with monitoring and demand for liquidity. Optimal incentives to monitor the firm suggest that large block shareholder investments be illiquid. But the liquidity premium on illiquid investments may be so high that it may be efficient to trade off optimal incentives for greater liquidity. Building on the fundamental complementarity between speculative monitoring (which increases the informativeness of prices) and active monitoring (which is enhanced when investments are more liquid), the paper then spells out the conditions on the underlying parameters under which more or less liquidity is warranted. Finally, the model is applied to the analysis of common exit provisions in venture capital financing.
\end{abstract}

\footnotetext{
${ }^{1}$ We are grateful to John Coates, Denis Gromb, Josh Lerner, Stuart Myers and Ailsa Roell for helpful suggestions. We thank participants at the NBER Corporate Finance Meetings of 14 April 2000 for comments. Contact Information: Please send all correspondence to: Patrick Bolton, Department of Economics, Princeton University, Princeton NJ 08544; phone: (609) 25840 37; fax: (609) 25864 19; email: pbolton@princeton.edu
} 


\section{Introduction}

A large fraction of the most successful US firms in the last decade have grown out of venture capital financing. This is most evident in the high technology, computer software, and biotechnology sectors. Venture capital (VC) is generally described as short to medium term investments by specialized funds in "high-growth, high-risk, firms that need equity capital to finance product development" ${ }^{2}$. VC funds provide firms not only capital and reputation but also managerial advice and intensive monitoring ( see Lerner (1995)). However, VCs' managerial involvement decreases over time as firms gain experience and reputation. At some point, for the successful ventures, it is more profitable to move away from venture capital financing by going public, switching to straight bank financing, or merging with another firm. In other words, $\mathrm{VC}$ financing is a temporary form of financing in a firm's life-cycle and an important aspect of the contracting relationship between VC funds and firms is the design of the exit mechanism for the fund ${ }^{3}$. This paper provides a first attempt at a formal analysis of this exit problem using the methodology of mechanism design theory.

An increasingly influential view is that controlling shareholders' ability to unwind their positions at any time must be restricted to ensure efficient monitoring. Otherwise, the argument goes, (controlling) shareholders will be tempted to "exit" before "voicing" their disapproval of management's actions. According to this view there is a trade-off between the liquidity of a controlling shareholder's stake and effective shareholder control. ${ }^{4}$ Yet, looking at recent data on the number of IPOs of VC financed firms and the aggregate amount of new capital invested into VC funds, Black and Gilson (1998) find a positive

\footnotetext{
${ }^{2}$ See Black and Gilson (1998).

${ }^{3}$ The average holding period for VC investors' shares in a portfolio's firm, is under 5 years (Sahlman 1990).

${ }^{4}$ In particular, see Coffee (1991); other authors such as Mayer (1988), Bhide (1993), Roe (1994) and Kojima (1995), further suggest that a strength of Japanese and German corporate governance systems is that they ensure better involvement in firms of large (institutional) shareholders by restricting their ability to trade controlling blocks in secondary markets. They argue that shareholder activism in the US and the UK can only work effectively when similar trading restrictions on active institutional investors are set up. Accordingly, they advocate the reversal of US stock market regulations which, they argue, have systematically pursued secondary market liquidity over effective shareholder control.
} 
correlation over time between $\mathrm{VC}$ investment turnover and the flow of capital to VC.

\section{Figure 1 here.}

At the same time, existing time series show that the average holding period in US venture capital firms (prior to exit by the VC fund), has decreased from about eight to less than five years over the past two decades. Many authors, including Black and Gilson, would suggest that the increase in the number of (ex-post) investment opportunities is the primary cause for the corresponding boom in venture-capital backed IPOs. However, Figure 1 tells us that the amount of capital invested in $\mathrm{VC}$ funds has also increased substantially over the recent period, and therefore one may wonder why the increase in the number of ex post investment opportunities, was not simply absorbed by the new venture capital funding, in a way that would have left the average holding period of each individual VC investment essentially unchanged. In other words, can we explain why the increased flow of capital to $\mathrm{VC}$ did not seem to have a noticeable offsetting effect on the average frequency of venture-capital backed IPOs? Is there instead some kind of a causal relationship between the VC fund supply and the IPO boom?

To discuss this and other aspects of exit in venture capital financing, we consider a contracting model with shareholder monitoring and securities trading. The model formalizes the relationship between an institutional investor (VC fund), its capital providers, firms, and potential buyers or underwriters, in an environment in which the VC fund is subject to liquidity shocks, and therefore values exit options. Our framework is set up to reflect the main stages of the financial life cycle of a firm. At the initial stage, the capital provider (or alternatively the firm) must determine whether to restrict liquidity (or "exit") in order to maintain incentives for active monitoring (or "voice") by the VC fund prior to exit. At a later stage, when more capital is needed or when the initial VC investors want to sell out (that is, when a liquidity shock occurs), the VC fund exits whenever this is allowed by the initial contract, and under the terms specified by that contract, which in turn may depend on the speculative information generated by potential buyers or underwriters. 
We first find that the optimal choice of liquidity depends on the underlying demand for liquidity of the active monitor and other investors, the accuracy of the firm's valuation at the time of exit, and the cost of speculative monitoring. Under some parameter values it may be optimal for the firm to restrict liquidity of the controlling block entirely, by say, not listing the firm on an exchange, or prohibiting resale. Under other configurations it may be optimal to make the controlling block and all other shares fully liquid. It may even be desirable to force "exit" of all shareholders (this can be achieved for example by writing so called drag-along agreements, whereby venture capitalists are required to sell their stake in a firm when it is put up for sale). Our analysis thus indicates that there is not always a trade-off between liquidity and control.

More specifically, we find that greater liquidity brings about greater control when: (i) the number of ex-post investment opportunities for the VC fund is high; (ii) a large amount of funds is supplied to the VC industry, so that the ex-ante opportunity cost of VC investments in the portfolio firm is low, and (iii) the valuation of the firm in a sale reflects the firm's fundamentals accurately. Each of these conditions appears to have been met in the past fifteen years in the US. In particular, our analysis reconciles the evidence on the increasing number of IPOs and that on the average holding period of VC investments (our point (ii)): namely, as a result of the increase in the flow of funds towards VCs, the cost of capital of VC funds has been reduced; this allowed VCs to make more liquid investments by taking bigger stakes in each venture; indeed, with more liquidity bigger stakes are required to preserve VCs incentives to actively monitor their entrepreneurs.

Next, when endogeneizing potential buyers'or underwriters' incentives to gather speculative information, we find that it is optimal to provide speculative monitors with options to buy equity. This also is consistent with the evidence on exit in venture capital financing; in particular, most venture capital firms in the US, either go public or end up being acquired by larger firms. We thus show that when companies decide to go public in order to create more liquidity they choose to do so by issuing equity rather than debt even if this involves a higher dilution cost. The basic reason is that equity creates greater incentives 
for speculative monitoring by potential buyers or underwriters than debt, and therefore the price of equity in the secondary market better reflects the information generated by the active monitor than the price of debt (see Benveniste and Spindt (1989) and Boot and Thakor (1997) for related observations).

There is a growing theoretical literature on Venture Capital, but to our knowledge, our paper is the first to focus on the design of exit clauses. There is, however, a small related theoretical literature on "exit" in Corporate Finance. The most closely related models to ours are by Kahn and Winton (1998) and Maug (1998). They also analyze the impact of a liquid stock market on monitoring by large block-holders, but their models in contrast to ours have small investors who face liquidity shocks and large investors who do not. Also these papers do not take a mechanism design approach to the optimal design of liquidity.

More recently, the model of Faure-Grimaud and Gromb (1999) also emphasizes the possible complementarity between active monitoring and secondary market valuation at the IPO stage. However, their paper also does not take a mechanism design approach aiming at determining the optimal level of liquidity, exit options and compensation structures for the different participants. Our concern here is to characterize the solution to an optimal contracting problem subject to incentive and individual rationality constraints for the various parties, and to show how this solution depends on the underlying parameters of the problem ${ }^{5}$.

While our optimal contracting approach is most appropriate for private ownership settings it can also shed new light on public ownership environments. First, corporations can enter agreements with large block holders that mimic some of the incentive and exit possibilities designed for a venture capitalist. Second, our paper provides a framework for assessing the impact of existing legal and regulatory constraints on insiders' exit.

The remainder of the paper is organized as follows. Section 2 develops the general framework: a principal, acting on behalf of uninformed investors, an entrepreneur, an

\footnotetext{
${ }^{5}$ The optimal design of the active monitor's (or VC fund's) contract, is a non-standard dynamic contracting problem that combines moral hazard with a Diamond- Dybvig (1983) type liquidity problem.
} 
active monitor (or venture capitalist) who can exert effort in order to reduce the manager's rents from shirking, and a speculative monitor who can acquire information about the firm's future performance. The active monitor is subject to liquidity shocks, and therefore may value contractual arrangements that provide him with an exit option prior to the payback stage where the firm's revenues are realized. Section 3 first characterizes the optimal contract for the active monitor and provides sufficient conditions under which this contract is liquid and allows her to sell her claims whenever she faces a liquidity shock. It then characterizes the optimal contract for the speculative monitor and analyzes how the two monitoring problems interact. Finally, Section 4 discusses various extensions and robustness checks, and derives some implications of our analysis for the design of venture capital agreements.

\section{Basic Model}

We divide time into three main phases or periods:

- a start-up stage $t=0$, where contracts are structured and investments made,

- a pay-back stage $t=2$, where the firm's revenues are realized and,

- a trading stage $t=1$, where the firm's initial investors may sell their stake to new investors.

Our analysis focuses mainly on the intermediate stage: whether and how stakes can be sold to new investors and more generally how the liquidity of initial investments should be designed. Before we turn to a description of the mechanism design problem we need to specify the firm's technology, preferences of participants (entrepreneur and investors) and their information structures. 


\subsection{The firm's technology}

At date $t=0$ the firm sets up a project at cost $I>0$. This project generates a random verifiable cash flow in period $t=2$ of

$$
\widetilde{R}= \begin{cases}r & \text { with probability } 1-p \\ r+\Delta & \text { with probability } p\end{cases}
$$

where $r>0$ and $\Delta>0$. The project is run by an entrepreneur who can affect the cash flow outcome through her actions. This is modeled by letting the probability $p$ be an endogenous variable. It can take two values, $p \in\left\{p_{L}, p_{H}\right\}$ where:

- $p=p_{L}=0$ if the entrepreneur shirks ${ }^{6}$,

- $p=p_{H}>0$ if she is diligent.

When the entrepreneur shirks she gets a private benefit denoted by $\beta>0$. To induce her not to shirk she would need to receive a financial reward, which compensates her for the loss of private benefits $\beta$. Compensating her for the full loss of private benefits may be too costly and a cheaper way of inducing her to work hard may be to monitor her actions. We shall allow for both financial incentives and monitoring to overcome this incentive problem.

\subsection{Investors}

Besides the entrepreneur, who is essential to run the project, there are potentially three types of investors involved in the firm:

- uninformed investors, e.g. limited partners in a venture capital fund, who limit their involvement to a passive financial investment,

\footnotetext{
${ }^{6}$ The assumption $p_{L}=0$ ensures that the active monitor always wants to exit at date $t=1$ when he has shirked. Our results extend with minor modifications to the general case where $p_{L}>0$, but since in this case it is possible that the active monitor may prefer not to exit at date $t=1$ when he shirks, the derivation of the optimal contract is slightly more involved.
} 
- an active monitor, e.g. the general partner in a venture capital fund, henceforth labelled 'venture capitalist', who takes a more active role and monitors the entrepreneur, and

- a speculative monitor, e.g. a buyer, an underwriter, or a speculator, who may gather information on the firm's performance from the outside and make speculative investments in period $t=1$ if shares are issued or sold.

All parties are risk-neutral. Uninformed investors and the speculative monitor have no binding wealth constraint. In contrast, the entrepreneur has no initial wealth, and the active monitor faces an opportunity cost of funds (even very wealthy venture capitalists or bankers do not have enough wealth to be able to invest in all investment opportunities that are open to them). Thus, we assume that the active monitor can free up funds for the project at a positive opportunity cost $\mu_{0}>1$ as in Holmstrom and Tirole (1997) and that any residual financing at date $t=0$ is provided by uninformed investors. We also assume that the entrepreneur and active monitor are protected by limited liability.

The role of the entrepreneur and uninformed investors in our model is straightforward. The role and objectives of the active and speculative monitors are less standard and require further elaboration.

1. The active monitor: The role of the active monitor in our model is to reduce the entrepreneur's private benefits from shirking by supervising her actions. This is modeled by assuming that when the entrepreneur is not monitored her private benefits are $\beta=B$. But when she is actively supervised by an active monitor her private benefits are reduced to $\beta=b<B$. The interpretation is that by supervising the entrepreneur the active monitor can reduce her scope for diversion of funds.

Active monitoring, however, involves a private cost $c>0$ for the monitor. It will only take place if the monitor has a financial incentive, which compensates him for incurring these costs. To simplify the strategic interaction between the active monitor and entrepreneur as much as possible we suppose that the monitor's decision 
to supervise or not is observed by the entrepreneur before she chooses her action. Thus, if the active monitor decides not to supervise the entrepreneur she will simply shirk $^{7}$.

The core economic issue in our model relating to active monitoring arises from the tension between two objectives: i) providing the active monitor with efficient financial incentives to monitor, and ii) letting the active monitor hold as liquid a stake as possible. We model the monitor's demand for liquidity by assuming that he is subject to liquidity shocks: with some probability the monitor would prefer to unwind his investment in the firm in period $t=1$ in order to reinvest the proceeds in a more profitable investment opportunity. More formally we assume that the active monitor's date $t=1$ utility function is given by:

$$
u\left(c_{1}, c_{2}\right)= \begin{cases}\mu_{1} c_{1}+c_{2} & \text { with probability } \lambda \\ c_{1}+c_{2} & \text { with probability }(1-\lambda)\end{cases}
$$

where $\mu_{1}>1$ is the scarcity value of funds for the active monitor at date $t=1$ if an alternative and more profitable investment opportunity arises at that date. This event, which we may refer to as a "liquidity shock" occurs with probability $\lambda$. When a more profitable investment opportunity arises the active monitor obviously prefers to unwind his investment in the firm at date $t=1$. We need to assume that $\mu_{1}$ is not too large. Specifically we assume that:

$$
\mu_{0}>\lambda \mu_{1}+(1-\lambda)
$$

Otherwise, an arbitrage opportunity exists between uninformed investors and the active monitor.

The problem with unwinding the active monitor's investment early is that in period $t=1$ the final realized value of cash flows is not known perfectly. As a result it is more difficult or more expensive to provide adequate financial incentives to the active

\footnotetext{
${ }^{7}$ We implicitly restrict the analysis to parameter values for which the entrepreneur cannot get financing if left unmonitored.
} 
monitor to supervise the entrepreneur. To see this, imagine that nothing is known about realized cash flows at date $t=1$. Then, if the active monitor is allowed to sell his stake in that period at its expected present value he gets no financial reward for actively monitoring the entrepreneur whenever he quits in period $t=1$. To preserve incentives for active monitoring, it is thus essential to bring the information about realized cash flows in period $t=2$ forward to period $t=1$. This can be done by "speculative investors" who monitor the firm from the outside.

2. The speculative monitor. His role is to assess the value of the firm at date $t=1$. At that time all actions have already been chosen and the probability distribution over future cash flows is determined. When he monitors, he receives a high or a low signal about future cash flows. We denote by $q_{H}$ (respectively $q_{L}$ ) the probability of receiving a high signal, when the entrepreneur has chosen the high effort level $p_{H}$ (respectively low effort level $p_{L}=0$ ).

For simplicity, we assume that realized cash flows are a sufficient statistic for managerial effort; in other words, that the speculator's signal conveys no new information beyond that contained in the final return. This implies that the only role of speculative monitoring is to bring information forward in time and not to provide supplementary information to fine tune entrepreneurial incentives. Let $\sigma \in(1 / 2,1)$ denote the conditional probability that the signal matches the return. Then we have:

$$
q_{i}=p_{i} \sigma+\left(1-p_{i}\right)(1-\sigma)
$$

Our assumption that cash flows are a sufficient statistic for managerial effort implies that the likelihood ratios on observing respectively a high final cash flow realization and a high signal at date $t=1$ are ranked as follows:

$$
\frac{p_{H}-p_{L}}{p_{H}}>\frac{q_{H}-q_{L}}{q_{H}} .
$$


We denote the likelihood ratios at respective dates $t=1$ and $t=2$ by

$$
\Lambda_{q}=\frac{q_{H}-q_{L}}{q_{H}} \text { and } \Lambda_{p}=\frac{p_{H}-p_{L}}{p_{H}}=1
$$

The closer $\Lambda_{q}$ gets to $\Lambda_{p}=1$, the better the quality of the signal generated by speculative monitoring, that is the more effective speculative monitoring is at producing information about the firm's performance.

We shall analyze the optimal contract for the active monitor in a first stage and take the existence of a signal at date $t=1$ as given. We only consider the endogenous production of this signal by speculative monitors in a second stage.

\subsection{Information structures and the timing of moves}

There are three incentive problems in our model. First, the entrepreneur's problem, which results from the unobservability of her choice of effort. Second, the active monitor's problem. His decision about whether to supervise the entrepreneur is observable by the entrepreneur but by no one else. Furthermore, the active monitor has private information about his liquidity need. Third, the speculative monitor's problem: his decision to monitor and the signal he observes are private information, so that he must be given financial rewards to induce him both to monitor and reveal his information truthfully.

The timing of moves of the different participants is as follows:

- At date $t=0$, the uninformed investors, the entrepreneur and the active monitor sign a comprehensive contract specifying how the contracting parties are compensated as a function of the revenue outcome at date $t=2$ and of the information that is reported by the active and speculative monitors at date $t=1$. We assume that the principal, acting on behalf of uninformed investors, makes the ex ante contractual proposals to the other parties (entrepreneur, active and speculative monitor) ${ }^{8}$.

\footnotetext{
${ }^{8}$ No change would arise if, as is sometimes done in the existing literature, we assumed instead that the owner of the technology is the contract designer.
} 
- Once the contract is signed and the investment project set up, the active monitor chooses whether to supervise the entrepreneur.

- Following the active monitor's choice the entrepreneur decides whether to shirk. As mentioned above, she observes the active monitor's choice before taking that decision.

- Following these action choices, the active monitor learns (privately) at date $t=1$ whether he faces a liquidity shock, that is whether the scarcity value of his funds at date $t=1$ is equal to $\mu_{1}$ or 1 . In case he announces a liquidity shock, the contract may call for the services of a speculative monitor to value the active monitor's claims and specify a compensation for the active monitor at date $t=1$ on the basis of the speculative monitor's report $q \in\left\{q_{L}, q_{H}\right\}^{9}$. The active monitor has no information about the outcome of speculative monitoring when declaring whether he faces a liquidity shock. We denote by $\psi>0$ the cost of generating a speculative signal.

- Finally, at date $t=2$ returns are realized and all parties are compensated as a function of the publicly observable realized returns and (when available) the previous period's reports of the active and speculative monitors.

We shall implicitly restrict our analysis to parameter values such that the net pledgeable income to uninformed investors is positive when the entrepreneur is actively monitored and consequently chooses $p=p_{H}$, but is negative when no active monitoring takes place and the entrepreneur shirks ${ }^{10}$.

\section{$2.4 \quad$ Feasible contracts}

Throughout most of the paper we shall assume that the contracting parties can commit to a long-term contract. We do not impose any restrictions on the set of feasible contracts. In

\footnotetext{
${ }^{9}$ Although for reasons of convenience the contracting problem is set up so that the conditional services of a speculative monitor are already committed at date $t=0$, the problem could easily be modified to allow for contracting with a speculative monitor only as of date $t=1$.

${ }^{10}$ See footnote 13 below for a more formal statement of this assumption.
} 
particular, monetary transfers can be made contingent on any observable variable. That is, they can be a function of the final revenue outcome (at date $t=2$ ) and the information that is reported by active and speculative monitors at date $t=1$. The contract must only satisfy the usual incentive compatibility, individual rationality, and/or limited liability constraints. In Section 4 we briefly discuss how the possibility of contract renegotiation at date $t=1$, affects the efficient outcome. There is no loss of generality in considering optimal compensation contracts for each agent separately. We begin with the entrepreneur and the active monitor:

1. The entrepreneur's compensation contract: Given our assumptions on the entrepreneur's preferences and the informativeness of signals at date $t=1$, the entrepreneur's optimal compensation package actually takes a very simple form. Since the entrepreneur is risk neutral and does not face any liquidity shock, and since signals at date $t=1$ are less informative about the entrepreneur's choice of action than cash flow realizations at date $t=2$, it is optimal to defer the entrepreneur's compensation entirely to date $t=2$ and not pay him anything before cash flow is realized. The entrepreneur's payment at date $t=2$ then depends on the cash flow realization. We denote these by $R^{e}(r)$ and $R^{e}(r+\Delta)$ respectively.

To provide incentives to work the entrepreneur should be rewarded for high cash flow and punished for low cash flow realizations. But since he is wealth-constrained and protected by limited liability the maximum punishment in the event of a low return is to pay him 0 . Thus, the entrepreneur's compensation boils down to a single, strictly positive number: $R^{e}(r+\Delta) \equiv R^{e}$.

2. The active monitor's compensation contract: To insure the active monitor against liquidity shocks it may be optimal to pay him a positive transfer at date $t=1$ on the basis of the realized (and truthfully reported) speculative signal. Again, to have incentives to monitor he should be rewarded only when a high signal at date $t=1$ or a high cash flow at date $t=2$ is realized (and he should receive nothing 
in the events of a low signal or a low cash flow outcome). Thus, his compensation contract has at most four strictly positive transfers $\left\{r^{a}\left(\mu_{1}\right), R^{a}\left(\mu_{1}\right), r^{a}(1), R^{a}(1)\right\}$, where:

(a) $r^{a}\left(\mu_{1}\right)$ denotes the active monitor's payoff at date $t=1$ contingent on a high signal when he reports a liquidity shock or scarcity value of funds of $\mu_{1}>1$;

(b) $R^{a}\left(\mu_{1}\right)$ denotes the date $t=2$ transfer contingent on a high cash flow realization when he reports $\mu_{1}$;

(c) $r^{a}(1)$ denotes the active monitor's payoff at date $t=1$ when he truthfully reports no liquidity shock; as we shall argue below (see footnote 10), it is (weakly) optimal to set $r^{a}(1)=0$ since signals at date $t=1$ are less informative than cash flows; hence, we shall use the less cumbersome notation $r^{a}$ to denote the active monitor's date $t=1$ payoff when he reports a liquidity shock, that is: $r^{a}=r^{a}\left(\mu_{1}\right)$;

(d) $R^{a}(1)$ denotes the date $t=2$ transfer contingent on a high cash flow realization when he reports no liquidity shock.

\section{The liquidity/monitoring trade-off.}

Before turning to a characterization of the active monitor's optimal contract consider briefly the entrepreneur's incentive problem. Given that he has been actively monitored the entrepreneur is better off working than shirking if and only if:

$$
p_{H} R^{e} \geq p_{L} R^{e}+b
$$

This incentive constraint ties down exactly the required minimum transfer that induces the entrepreneur to work:

$$
R^{e} \geq \frac{b}{p_{H}-p_{L}}=\frac{b}{p_{H}} .
$$




\subsection{The active monitor's contract}

The active monitor's incentive problem is a non-standard dynamic moral hazard problem because it has a stochastically evolving opportunity cost of funds and the realized value at date $t=1$ is private information. Viewed from another perspective the active monitor's problem here is a combination of a Diamond and Dybvig (1983) type liquidity problem and a moral hazard problem.

\subsubsection{The active monitor's incentive problem}

The optimization problem with respect to transfers to the active monitor can be set up as a cost minimization problem subject to an individual rationality constraint and to two incentive constraints. The individual rationality constraint guarantees that the amount $I^{a}$ initially invested in the project by the active monitor times the scarcity value $\mu_{0}$ is less than or equal to his expected utility $U^{a}$ under the contract. The first incentive constraint guarantees that the monitor actively monitors the entrepreneur. The second that he truthfully reports his liquidity shock.

More formally, using the fact that the individual rationality constraint of the active monitor is binding in equilibrium ${ }^{11}$, and letting $P^{a}$ denote the expected monetary payment to the active monitor, an optimal contract for the venture capitalist, is one that minimizes the net expected cost of active monitoring, namely:

$$
P^{a}-I^{a}
$$

where $I^{a}$ is the active monitor's investment in the project. The individual rationality constraint of the active monitor is binding when $I^{a}=\frac{1}{\mu_{0}} U^{a}$, where $\mu_{0}$ is the scarcity value of venture capital funds and $U^{a}$ is the expected gross utility of the active monitor if he signs the contract. We have:

$$
\text { - } U^{a}=\lambda\left(q_{H} \mu_{1} r^{a}+p_{H} R^{a}\left(\mu_{1}\right)\right)+(1-\lambda) p_{H} R^{a}(1)-c \text { and }
$$

\footnotetext{
${ }^{11}$ If this constraint were not binding, then the Principal could increase his net expected value by slightly reducing $r^{a}, R^{a}(1)$, and $R^{a}\left(\mu_{1}\right)$ in such a way that both the individual rationality constraint and the two incentive constraints of the active monitor remain satisfied.
} 
- $P^{a}=\lambda\left(q_{H} r^{a}+p_{H} R^{a}\left(\mu_{1}\right)\right)+(1-\lambda) p_{H} R^{a}(1)$,

Therefore, we can express the optimal contracting problem for the active monitor as the following minimization problem:

$$
\min _{\left\{r^{a}, R^{a}\left(\mu_{1}\right), R^{a}(1)\right\}}\left\{\lambda\left[q_{H}\left(1-\frac{\mu_{1}}{\mu_{0}}\right) r^{a}+p_{H}\left(1-\frac{1}{\mu_{0}}\right) R^{a}\left(\mu_{1}\right)\right]+(1-\lambda)\left(1-\frac{1}{\mu_{0}}\right) p_{H} R^{a}(1)\right\}
$$

subject to:

$$
\lambda\left[q_{H} \mu_{1} r^{a}+p_{H} R^{a}\left(\mu_{1}\right)\right]+(1-\lambda) p_{H} R^{a}(1)-c \geq \lambda q_{L} \mu_{1} r^{a}+(1-\lambda) q_{L} r^{a}
$$

and

$$
\left\{\begin{array}{ll}
q_{H} \mu_{1} r^{a}+p_{H} R^{a}\left(\mu_{1}\right) \geq p_{H} R^{a}(1) & (a) \\
p_{H} R^{a}(1) \geq q_{H} r^{a}+p_{H} R^{a}\left(\mu_{1}\right) & (b)
\end{array}\right\}
$$

The first constraint (7), is the active monitor's ex ante incentive constraint with respect to monitoring effort. The RHS of this constraint reflects the fact that a shirking monitor has the option to exit at date $t=1$ in order to evade the negative consequences from shirking by getting out before anyone is aware of his misconduct. He chooses to exercise this option whenever $r^{a}>0$ since in that case his payoff from exiting $q_{L} r^{a}$ is greater than his payoff from staying, which is just equal to zero when he chooses $p_{L}=0$. The second set of constraints (8) ensure truthful reporting of the liquidity shock conditional on not shirking $^{12}$.

It is easy to see that at the optimum, constraint (7) is always binding. Indeed, if it were not then the obvious solution to the subconstrained program in which (7) is ignored is $r^{a}=R^{a}\left(\mu_{1}\right)=R^{a}(1)=0$. But this solution clearly violates constraint (7).

\footnotetext{
${ }^{12}$ Assuming that the active monitor's reward $r^{a}(1)$ in the absence of a liquidity shock is equal to zero, involves no loss of optimality. To see this, note that since $\frac{q_{H}-q_{L}}{q_{H}}<\frac{p_{H}-p_{L}}{p_{H}}$ a move from a contract with $r^{a}(1)>0$ to a contract with $r^{a}(1)=0$, keeping the expected transfer to the active monitor conditional upon not shirking constant, relaxes both incentive constraints. Therefore the optimal contract is such that $r^{a}(1)=0$.
} 


\subsubsection{Optimal liquidity design}

Using the fact that (7) is binding at the optimum, and then substituting for $(1-\lambda) p_{H} R^{a}(1)$ from (7) into the principal's objective function, we can reformulate the above program as:

$$
\min _{\left\{r^{a} \geq 0, R^{a}\left(\mu_{1}\right) \geq 0\right\}}\left\{\left[\lambda\left(1-\frac{\mu_{1}}{\mu_{0}}\right) q_{H}-\lambda\left(1-\frac{1}{\mu_{0}}\right) \mu_{1}\left(q_{H}-q_{L}\right)+(1-\lambda)\left(1-\frac{1}{\mu_{0}}\right) q_{L}\right] r^{a}+\frac{c}{\mu_{0}}\right\}
$$

subject to:

$$
\left\{\begin{array}{l}
q_{H} \mu_{1} r^{a}+p_{H} R^{a}\left(\mu_{1}\right) \geq p_{H} R^{a}(1) \quad(a) \\
p_{H} R^{a}(1) \geq q_{H} r^{a}+p_{H} R^{a}\left(\mu_{1}\right) \quad(b)
\end{array}\right\} .
$$

Now, let

$$
\mu^{*}=\frac{\lambda q_{H}+\left(1-\frac{1}{\mu_{0}}\right)(1-\lambda) q_{L}}{\lambda\left[\frac{q_{H}}{\mu_{0}}+\left(1-\frac{1}{\mu_{0}}\right)\left(q_{H}-q_{L}\right)\right]},
$$

then when $\mu_{1}<\mu^{*}$, it is straightforward to verify that the term in square brackets in the objective function is positive, so that it is optimal to set $r^{a}=0$ and $R^{a}(1)=R^{a}\left(\mu_{1}\right)$. On the other hand, if $\mu_{1} \geq \mu^{*}$, it is optimal to set $r^{a}$ as large as possible, subject to (8). This in turn implies that the second constraint in (8) is binding at the optimum.

This result is not too surprising. When $\mu_{1}$ is close to 1 the active monitor is essentially indifferent as to when he gets paid. Giving him an exit option by offering him a liquid contract with $r^{a}>0$, would then worsen the monitoring incentive problem without yielding any substantial liquidity benefits ${ }^{13}$. When $\mu_{1}$ is large, on the other hand, providing the active monitor with an exit option may increase his monitoring incentives ${ }^{14}$.

We can now solve for the active monitor's optimal contract. We consider in turn the case of a patient $\left(\mu_{1}<\mu^{*}\right)$ and an impatient $\left(\mu_{1}>\mu^{*}\right)$ active monitor.

${ }^{13}$ More precisely, for $\mu_{1}$ close to 1 , we have

$$
\mu_{1}\left(\frac{q_{H}-q_{L}}{q_{H}}\right)<\frac{p_{H}-p_{L}}{p_{H}}=1 .
$$

Then, if $r^{a}>0$ one can lower $q_{H} r^{a}$ by some amount $d r$, while at the same time increasing $p_{H} R^{a}\left(\mu_{1}\right)$ by $\mu_{1}\left(\frac{q_{H}-q_{L}}{q_{H}}\right) d r<d r$, without violating the effort incentive constraint of the active monitor. In other words, relying on second period returns provides higher powered incentives to the active monitor than relying on the first period signal generated by speculative monitoring.

${ }^{14}$ In particular, for $\mu_{1}$ large, we have: $\mu_{1}\left(\frac{q_{H}-q_{L}}{q_{L}}\right)>\frac{p_{H}-p_{L}}{p_{L}}=1$, so that relying on the speculative signal at date $t=1$ provides higher powered effort incentives to the active monitor than relying on date $t=2$ returns. 
1. Patient monitor case: $\mu_{1}<\mu^{*}$.

(a) We have seen that, in this case, the optimal contract is illiquid, with $r^{a}=0$ and $R^{a}\left(\mu_{1}\right)=R^{a}(1)=\frac{c}{p_{H}}$, and the principal's expected cost from hiring an active monitor is:

$$
C_{A}^{I L}=\left(1-\frac{1}{\mu_{0}}\right) c+\frac{c}{\mu_{0}}=c,
$$

where the superscript $I L$ stands for "Illiquid".

\section{Impatient monitor case: $\mu_{1}>\mu^{*}$.}

In this case we know that constraint ( $8 \mathrm{~b})$ is binding, that is:

$$
R^{a}(1)=\frac{q_{H}}{p_{H}} r^{a}+R^{a}\left(\mu_{1}\right)
$$

Using this together with the active monitor's effort incentive constraint, which we can rewrite as:

$$
\left(q_{H}-q_{L}\right)\left(\lambda \mu_{1}+1-\lambda\right) r^{a}+p_{H} R^{a}\left(\mu_{1}\right)=c
$$

one can substitute for $R^{a}(1)$ and $r^{a}$ in the principal's objective function, so that the above minimization program reduces to:

$$
\min _{R^{a}\left(\mu_{1}\right)}\left\{F R^{a}\left(\mu_{1}\right)+\frac{c}{\mu_{0}}\right\}
$$

where,

$$
F=\left(1-\frac{1}{\mu_{0}}\right)-\frac{\left[\lambda\left(1-\frac{\mu_{1}}{\mu_{0}}\right)+(1-\lambda)\left(1-\frac{1}{\mu_{0}}\right)\right] q_{H}}{\left(q_{H}-q_{L}\right)\left(\lambda \mu_{1}+1-\lambda\right)} .
$$

It is easy to check that $F$ is positive whenever $\mu_{1}>\mu^{*}$. It is thus optimal to set

$$
R^{a}\left(\mu_{1}\right)=0, r^{a}=\frac{c}{\left(q_{H}-q_{L}\right)\left(\lambda \mu_{1}+1-\lambda\right)} \text { and } R^{a}(1)=\frac{q_{H}}{p_{H}} r^{a}
$$

with a resulting cost for the principal - including the expected cost of acquiring the speculative signal $\lambda \psi$ at date $t=1$ - equal to: 


$$
C_{A}^{L}=\frac{\left[\lambda\left(1-\frac{\mu_{1}}{\mu_{0}}\right)+(1-\lambda)\left(1-\frac{1}{\mu_{0}}\right)\right] c}{\left[\lambda \mu_{1}+(1-\lambda)\right] \Lambda_{q}}+\frac{c}{\mu_{0}}+\lambda \psi,
$$

where the superscript $L$ stands for "liquid" ${ }^{15}, 16$.

Now, if we rewrite the cut-off level of impatience $\mu^{*}$ as:

$$
\mu^{*}=\frac{\lambda+(1-\lambda)\left(1-\frac{1}{\mu_{0}}\right)\left(1-\Lambda_{q}\right)}{\lambda\left[\Lambda_{q}\left(1-\frac{1}{\mu_{0}}\right)+\frac{1}{\mu_{0}}\right]},
$$

one can immediately verify that when $\psi=0, C_{A}^{L} \quad C_{A}^{I L}$ if and only if $\mu_{1} \geq \mu^{*}$. More generally, combining our analyses of the patient and the impatient active monitor cases, we obtain the following central result:

Proposition 1 : There exists a cut-off opportunity cost $\widehat{\mu} \geq \mu^{*}$, where $\mu^{*}=\frac{\lambda+(1-\lambda)\left(1-\frac{1}{\mu_{0}}\right)\left(1-\Lambda_{q}\right)}{\lambda\left[\Lambda_{q}\left(1-\frac{1}{\mu_{0}}\right)+\frac{1}{\mu_{0}}\right]}$, such that:

(a) It is optimal to offer a liquid contract with $r^{a}>0$ and $R^{a}\left(\mu_{1}\right)=0$ when $\mu_{1}>\widehat{\mu}$, and to offer an illiquid contract with $r^{a}=0$ otherwise ${ }^{17}$.

(b) The cut-off opportunity cost $\widehat{\mu}$ above which the optimal contract of the active monitor becomes liquid, is a decreasing function of both $\lambda$ and $\Lambda_{q}$ and it is an increasing function of $\mu_{0}$ and $\psi$.

(c) $\widehat{\mu}>\mu^{*}$ for $\psi>0$.

Proof: see the discussion above.

The intuition behind our comparative statics results is as follows. First, the higher is $\lambda$, the probability of a liquidity shock at date $t=1$, the higher the active monitor's

\footnotetext{
${ }^{15}$ The assumption that the firm's pledgeable income is positive if and only if the entrepreneur is actively monitored, can now formally be expressed by the inequalities:

$$
r+p_{H} \Delta-\psi-\min \left\{C_{A}^{I L}, C_{A}^{L}\right\}-b>I>r .
$$

${ }^{16}$ Note that if the assumption $\mu_{0}>\lambda \mu_{1}+(1-\lambda)$ which ruled out the possibility of arbitrage between uninformed investors and the active monitor, is violated, then it is optimal to set $r^{a}=\frac{\Lambda_{q} p_{H} R^{a}(1)}{q_{H}}=+\infty$, so that $C_{A}^{L}=-\infty$ !

${ }^{17}$ Throughout this section, we implicitly restrict attention to values of $\mu_{1}$ such that $\mu_{0}>\lambda \mu_{1}+(1-\lambda)$, so that there is no arbitrage between uninformed investors and the active monitor. Thus, liquid contracts are actually optimal for $\mu_{1} \in\left[\widehat{\mu}, \frac{\mu_{0}-(1-\lambda)}{\lambda}\right)$ and they are never optimal whenever this interval is empty.
} 
preference for liquidity and therefore the higher the benefits from providing him with an exit option. Second, the higher $\Lambda_{q}$ the lower the increase in agency cost involved in offering a liquid instead of an illiquid contract. Third, the comparative statics result with respect to $\mu_{0}$, the scarcity value of venture capital funds at date $t=0$, are driven by the considerations that, as the principal must pay more to attract venture capital ( $\mu_{0}$ goes up), he is less willing to offer the more expensive liquid contract. Note that a liquid contract raises both the date $t=1$ and $t=2$ payments and the active monitor's investment contribution at date $t=0$.

Our comparative statics results with respect to $\mu_{0}$ may thus provide an explanation for the recently observed reduction in the average age of technology start-ups before they go public. Our explanation would be that as more money flows into the venture capital industry the terms demanded by Venture Capital funds go down (in terms of our model $\mu_{0}$ goes down) and therefore the relative costs of offering the more efficient liquid contracts go down. This is an alternative explanation to the one that is commonly given that firms tend to go public sooner because the market for IPOs is currently very hot. Note that these two explanations are not inconsistent. Also, unfortunately, disentangling the two effects empirically appears to be very difficult.

\subsection{The speculative monitor's contract}

So far we have taken the existence of a signal of the firm's future cash flow at date $t=1$ as given. In practice, however, information about future cash flows is acquired endogenously by various market participants, which we have labelled "speculative monitors". As we noted earlier this information can be acquired only at cost $\psi>0$. Also, whether a speculative monitor actually sinks the cost to obtain this signal is private information. In addition, the signal he observes is also private information. Therefore, the principal must design a contract with the speculative monitor that induces him to both gather and truthfully reveal his information.

When designing this contract the principal has to evaluate the speculator's incentives 
in response to all possible action choices by the active monitor. We begin by characterizing the optimal contract in response to the choice of action $p_{H}$ by the active monitor. We then consider the speculator's incentives in response to the active monitor's choice of $p_{L}$ under the latter contract and show that multiple equilibria may obtain under that contract for the speculator and under the contract characterized in proposition 1 for the active monitor. Finally, we show how the active monitor's contract must be modified to ensure unique implementation of the second best outcome.

\subsubsection{An optimal contract}

As it turns out, the speculative monitor's contract can take a very simple form in our model. The principal can offer the speculative monitor a call option (which expires at the end of period 1) allowing him to purchase a fraction $s$ of the firm's shares at an exercise price $e$. As we show below, there is a range of values $\{s, e\}$ such that: i) the speculative monitor is induced to monitor and reveal truthfully his observed signal and ii) his individual rationality constraint is binding.

The exercise price $e$ should be set so that the speculative monitor prefers not to exercise if he gets a low $(L)$ signal, but exercises the option if the signal is high $(H)$.

In other words, the exercise price $e$ must satisfy the condition:

$$
m_{H}^{H} \geq \frac{e-r}{\Delta} \geq m_{H}^{L}
$$

where,

$$
m_{H}^{H}=\frac{\sigma p_{H}}{\sigma p_{H}+\left(1-p_{H}\right)(1-\sigma)} ; \text { and } m_{H}^{L}=\frac{p_{H}(1-\sigma)}{p_{H}(1-\sigma)+\left(1-p_{H}\right) \sigma}
$$

are the probabilities of a high date $t=2$ cash flow conditional on observing, respectively,

signals $H$ and $L$. Since $\sigma>1 / 2$, the conditional probabilities are such that $m_{H}^{H}>m_{H}^{L}$. It is therefore possible to find an exercise price $e$ satisfying condition (12). Under this contract, exercising the option is tantamount to (truthfully) revealing the signal $H$ and not exercising to revealing $L$. 
Having obtained the option, the speculative monitor has an incentive to pay the acquisition cost $\psi$ in order to obtain an informative signal if and only if:

$$
q_{H}\left(m_{H}^{H} \Delta+r-e\right) s-\psi \geq \max \left\{0, p_{H} \Delta+r-e\right\} s .
$$

Finally, his individual rationality constraint is given by

$$
q_{H}\left(m_{H}^{H} \Delta+r-e\right) s-\psi \geq 0 .
$$

As long as $p_{H} \Delta+r>e$, the incentive constraint (13) can be relaxed by increasing the exercise price $e$. Therefore, the exercise price that minimizes the required amount $s$ of shares pledged to the speculative monitor is obtained by setting $e=p_{H} \Delta+r$, substituting this value in (13) and solving ${ }^{18}$ :

$$
q_{H}\left(m_{H}^{H}-p_{H}\right) \Delta s=\psi
$$

Thus, under this contract the speculative monitor makes zero net expected profits and the principal pays an expected cost $\psi$ to obtain the date $t=1$ signal. We summarize this discussion in the following proposition.

Proposition 2 An optimal incentive contract for the speculative monitor is a call option with exercise price: $e=p_{H} \Delta+r$, and number of shares: $s=\frac{\psi}{q_{H}\left(m_{H}^{H}-p_{H}\right) \Delta}$.

Proof: See the discussion above.

This proposition establishes that it is (weakly) optimal to provide the speculative monitor with options to purchase equity at date $t=1$. In particular, issuing (safe) debt instead of equity in a public offering at date $t=1$ is suboptimal because it does not provide the buyers or underwriters of the issue any incentive to acquire information about the future value of the firm. In other words, going public by issuing safe debt would deprive the firm of valuable signals, which would improve the incentive contract with the active

\footnotetext{
${ }^{18}$ Intuitively, any option obtained for free with exercise price such that $p_{H} \Delta+r>e$ would give a free gift to the speculative monitor even if he does no monitoring. To maximize incentives it is best to eliminate this gift.
} 
monitor. Thus, our analysis provides one explanation for why firms typically choose to go public by issuing equity and not debt, as a Myers and Majluf (1984) type analysis would predict. If an important goal of firms going public is to obtain information about its future value from equilibrium prices in the secondary market then these firms may be prepared to pay a dilution cost to obtain this information.

\subsubsection{Multiple equilibria and unique implementation}

Unfortunately, the optimal contracts for the active and speculative monitor derived above do not always uniquely implement the second best outcome. Indeed, multiple equilibria may obtain under these contracts. Specifically, an inefficient equilibrium in which the active monitor chooses low effort, and the speculative monitor does not invest in information may exist along with the efficient equilibrium. To see this, observe that if the active monitor is expected to choose $p_{L}=0$, it is optimal for the speculative monitor never to exercise the call option and therefore not to acquire any information. Conversely, if the speculative monitor is not expected to exercise the call option then the active monitor's best response may be to choose $p_{L}=0$ instead of $p_{H}$. This is the case whenever ${ }^{19}$ :

$$
p_{H} R^{a}(1)<c
$$

Note that this condition is consistent with the active monitor's effort incentive constraint (10). Both conditions can hold in particular when $\lambda$ and/or $\mu_{1}$ are large. Thus, if conditions (10) and (15) both hold there exists an inefficient equilibrium along with the efficient equilibrium characterized above.

The principal could stop here and hope for the best, or he could modify the active monitor's contract to ensure unique implementation of the efficient equilibrium.

Unique implementation requires that the active monitor's effort incentive constraint (7) as well as

$$
\left.p_{H} R^{a}(1)\right) \geq c
$$

\footnotetext{
${ }^{19}$ The LHS of this condition, reflects the fact that an active monitor who anticipates no speculative monitoring to take place, will systematically announce no liquidity shock; this, in turn, follows from the fact that $R^{a}\left(\mu_{1}\right)=0$ if the contract is liquid, as shown in Section 3.1 above.
} 
be satisfied under the optimal contract ${ }^{20}$.

When

$$
\Lambda_{q}\left(\lambda \mu_{1}+1-\lambda\right) \quad 1
$$

constraint (16) is automatically satisfied by the optimal contract for the active monitor derived in Proposition 1, so that there is a unique efficient equilibrium under this contract. On the other hand, when the opposite inequality holds,

$$
\Lambda_{q}\left(\lambda \mu_{1}+1-\lambda\right)>1
$$

then the active monitor's contract must be derived under the additional constraint (16) which of course will be binding in this case. Yet, as shown in the Appendix, the analysis in section 3.1 remains essentially valid and the optimal contract turns out to be similar to the one derived in Proposition 1. The main substantive difference is that it may be optimal to reduce liquidity to strengthen the active monitor's incentives.

\section{Discussion}

We begin by discussing informally a number of directions in which the theory can be extended.

\subsection{Extensions}

\section{(a)Hot-issue markets}

Decisions to go public are influenced by the ease of fund-raising; indeed the vast majority of IPOs occur at market peaks (Lerner 1994). IPOs do well in hot-issue markets presumably because they create stores of value in states in which loanable funds are plenty and stores of value scarce.

\footnotetext{
${ }^{20}$ When both constraints are satisfied it is a dominant strategy for the active monitor to choose $p_{H}$ so that the inefficient equilibrium is eliminated. An alternative potential way of achieving unique implementation could be to make information acquisition and truthful revelation by the speculative monitor a dominant strategy. But this is not possible when $p_{L}=0$, for then there is no valuable information to be collected by the speculative monitor. If, however, $p_{L}>0$ then it is possible and desirable to achieve unique implementation by selling a put (instead of a call) option on the firm to the speculative monitor under which it is a dominant strategy for the speculator to acquire the date $t=1$ signal.
} 
Formally, the aggregate shock determining whether the market is hot or cold, can be introduced into our model by letting the price that uninformed investors are willing to pay at date $t=1$ for a share yielding a unit expected income at date $t=2$ vary across states of nature. We can then consider two cases. In the first case, contracts contingent on the realization of the macroeconomic shock can be written at date $t=0$. The analysis is then a straightforward extension of that in Section 3. The new insight obtained from this analysis is that the liquidity of the active monitor's claim may now be contingent on the realization of the macroeconomic shock: An IPO being more profitable in a hot market, it may be optimal to make the active monitor's claim be liquid in the event of a hot market at date $t=1$ and illiquid in the event of a cold market. Note that in contrast to the predictions of a standard moral hazard incentive problem the active monitor's expected payoff may then depend on a (macroeconomic) variable he has no control over.

When the macroeconomic shock is observable but not directly verifiable, it is still the case that some information about this shock can be recovered from the price that shares fetch at the IPO. For example, one can let the active monitor decide whether to go public at date $t=1$, and if he chooses so, reward him only if the sale price is very high, meaning that he is likely to have monitored and the market is hot. This makes the active monitor's reward in case of exit even more nonlinear (although not more risky).

(b) Renegotiation

We have assumed that the initial plan designed at the outset is always implemented and that there is no renegotiation. Established venture capitalists may be able to build a reputation for abiding by the initial plan or create an underlying situation where they have no alternative but to stick to the plan by choosing not to line up prospective future buyers at the time of contracting. In general, however, renegotiation cannot be ruled out.

It may thus be worth enriching the model by looking at whether the parties would not want to renegotiate to their mutual benefit during the course of their relationship, and, if so, how exit design would be altered.

Renegotiation has no impact if the optimal contract is a liquid one since the allocation 
is then ex post efficient. In contrast, the illiquid contract is ex post inefficient since the active monitor keeps his stake until date 2 even when he faces a liquidity shock. As is often the case in optimal contracting, ex ante incentives are created by an ex post distortion that the parties will want to renegotiate away. The parties here have an incentive when date $t=1$ comes to agree to let the active monitor exit at that date at a discount relative to the value of his long term claim. The possibility of such renegotiation would then bring about more liquidity than would be desirable from an ex-ante perspective ${ }^{21}$. It is conceivable that adequately balanced regulatory intervention limiting exit at date $t=1$, perhaps of the kind envisioned by Coffee (1991) and others, might then provide an efficiency improving countervailing force.

(c) IPO underpricing

Our model has not made any assumption as to how the sale of shares proceeds. In particular, underpricing may occur if the IPO auction exhibits rationing as in Rock (1986). The level of underpricing will in general depend on the asymmetry of information between investors and the speculator. If this asymmetry of information covaries with the uncertainty about the quality of active monitoring (a covariation that can easily be built into the theoretical framework), then underpricing is less pronounced when the active monitor is more reputable, as the evidence for the venture capital industry by Barry, Muscarella, Peavy and Vetsuypens (1990) suggests.

\subsection{Exit design in venture capital agreements}

Our model can be interpreted in several different ways. One interpretation is that the active monitor is a CEO of a publicly traded firm. The CEO is expected to remain a limited time on the job, but his decisions and monitoring activities may have long run effects on the performance of the corporation. In designing the CEO's compensation

\footnotetext{
${ }^{21}$ See Fudenberg and Tirole (1990), Ma (1991) and Matthews (1995) for an analysis of renegotiation in a dynamic optimal contracting problem with moral hazard. Their analyses apply to our problem with small modifications (to include liquidity shocks). One might expect from their analyses that the anticipation of renegotiation at date $t=1$ might lead to an equilibrium outcome where the active monitor mixes between $p_{H}$ and $p_{L}$, and as a result renegotiation leads to only partial liquidity provision at date $t=1$.
} 
package the board of directors must then determine how liquid the CEO's stake should be in similar terms as we have outlined in this paper. Another interpretation is that the active monitor is some large pension or mutual fund engaging in some form of shareholder activism. As Coffee (1991) has suggested the investment fund would then face a trade-off between liquidity and incentives. However, contrary to his claims our analysis suggests that a highly liquid secondary market providing potentially large speculative gains to speculators could actually induce more not less active monitoring.

We believe, however, that our model fits best the interpretation that the active monitor is either a bank engaged in a long term relation with the firm or a venture capitalist. In the remainder of this section we discuss in greater detail common exit clauses in venture capital contracts and how they can be rationalized on the basis of the analysis in this paper.

(a) Planning of exit

Venture Capital (VC) contracts reveal that venture capitalists carefully plan their exit. Indeed, one of the most important issues for $\mathrm{VC}$ investors in negotiations with the entrepreneur concerns the allocation of registration rights. If $\mathrm{VC}$ investors hold a minority stake their exit will depend on decisions reached by majority shareholders. Therefore VC investors often require a registration rights agreement giving them the right either to have their shares included in an IPO (so called "piggyback rights") or to request that an IPO or private placement of shares take place (so called "demand rights") (see Bartlett 1994). Venture capitalists may also hold warrants, which the company must repurchase at an attractive price for the venture capitalist if the company does not go public within, say, five years (see Lerner 1999, p.339). In return for granting such rights, however, the entrepreneur often insists on a right to veto proposals to go public in the first three years ( see Levin 1995) ${ }^{22}$. Another important limitation on VC exit is that following an IPO there is usually a six-month lock-up period contracted with underwriters, during which the VC investor must retain a majority of their shares after the IPO.

\footnotetext{
${ }^{22}$ Alternatively, the entrepreneur may have the right to preempt by purchasing all shares of the venture capitalist at a price specified by a formula.
} 
Most VC agreements usually specify that the private equity or venture capital fund will dissolve after a period of no more than 10 to 13 years (see Gompers and Lerner 1999, p.240). But there is evidence suggesting that VC investors generally do not seem to hold their shares for such a long period. The average holding period is under 5 years (Sahlman 1990).

To be sure, the exact date of exit is generally not specified at the outset. Neither does the theory predict that it should. For one thing, under the liquid contract, the date of liquidation depends on the realization of the active monitor's liquidity needs. Furthermore, as discussed in Section 4.1, the exact date of liquidation may depend on the state of the placements market.

(b) Speculative monitoring and equity-based exit

General partners in venture capital funds hold fairly risky claims (usually convertibles and warrants, and sometimes common stocks). There are two main avenues for exit. One is a private placement or sale of the firm to a (usually larger) buyer. The other is an IPO. The consequences of these two modes of exit for the venture capitalist are largely similar $^{23}$. The "speculator" of the model is the buyer in case of a sale and the underwriter and the stock analysts in case of an IPO.

It is widely accepted in the venture capital community that equity-based exit, whether through an IPO or a sale, is key to the measurement of the performance of the entrepreneurventure capitalist team. Indeed, a precondition for a sale is often that all convertible debt be converted prior to putting the company up for sale or an IPO (see Bartlett 1994). To facilitate the sale of the company the general partner sometimes requests the right to drag along the other investors when he finds one (or several) buyers to purchase the company. A drag along covenant allows the general partner to force exit by the entrepreneur and by limited partners in case he finds a buyer. Similarly, a necessary condition for a successful IPO is that enough stocks be traded in order to attract enough attention by

\footnotetext{
${ }^{23}$ This is not so for the entrepreneur, who may be able to reassume some of her control rights in case of an IPO, but not in case of a sale. Berglof (1994) builds a theoretical model of the distributional conflicts associated with the sale of a company.
} 
investors and induce speculative monitoring. Such requirements can be viewed as ways of providing speculative monitors with enhanced incentives to acquire information, thereby facilitating the exit of the venture capitalist.

(c) Determinants of the intensity of liquidity needs

Our theory predicts that the venture capitalist's contract should be more liquid, the more intense and the more frequent the liquidity shock (the higher $\mu_{1}$ and $\lambda^{24}$ ). Factors that may impact the active monitor's liquidity needs include:

- Reputation: Well-established venture capitalists can raise large sums of money on short notice. The certification provided by the exit mechanism is less important for them than for less reputable venture capitalists. Our theory is therefore consistent with the observation of "grandstanding" (see Gompers 1996). The evidence shows that firms backed by young venture capital firms are also younger at the IPO stage. This observation is inconsistent with the following "natural" theory linking reputation and liquidity: a reputable venture capitalist should be more concerned about losing his reputation, and therefore could be allowed to exit earlier. It is, however, consistent with the explanation that more experienced venture capitalists do not need to liquidate their stakes in order to levy money for new investments (their " $\mu_{1}$ " is lower).

- Credit crunch: investment opportunities are particularly attractive when other large investors such as banks and insurance companies suffer a credit crunch or are imposed tighter restrictions on risky investments. One would therefore identify a credit crunch episode as one in which $\mu_{1}$ is large for venture capitalists ${ }^{25}$.

- Hot-issue markets: As discussed in Section 4.1, one would expect venture capitalists to have a high willingness to exit in a hot-issue market.

\footnotetext{
${ }^{24}$ It is hard to distinguish empirically between $\mu_{1}$ and $\lambda$. Our two-point distribution is a special case of a general distribution over the realization of $\mu_{1}$.

${ }^{25}$ See Lerner (1999, p.337).
} 


\section{Conclusion}

This paper provides a first study of the optimal design of active monitors' exit option. An active monitor's claim is more likely to be liquid, the more intense and frequent his liquidity needs; the more informative the speculative monitoring (in a sale, IPO or secondary market); and the scarcer the active monitor's loanable funds at the date of the initial outlay. In particular, we have argued that claims of active monitors should be more liquid when more money flows into the venture capital industry. The reason is that the returns demanded by Venture Capital Funds are then lower and therefore the relative cost of offering a more efficient liquid contract is reduced. Now, turning to the optimal contract for the speculative monitor, we have shown that it is (weakly) optimal for a venture capital firm to go public by issuing (options to purchase) equity rather than safe debt in order to provide the buyers or underwriters with the appropriate incentives to acquire information, which in turn can help improve the incentive contract with the active monitor.

While we argued that our theory is basically consistent with existing evidence on venture capital, further empirical validation is called for. Also, the theory should be extended in a number of directions, both to build a richer account of venture capital agreements (e.g relative to the choice of exit through a sale or an IPO, and to the allocation of control rights among the general partners, the limited partners, and the entrepreneur) and to analyze the aggregate dynamics of venture capital loanable funds and investment. We hope research in these directions and others will develop in the near future. 


\section{Appendix}

When $\Lambda_{q}\left(\lambda \mu_{1}+1-\lambda\right)>1$ the optimal contract for the active monitor which uniquely implements the second best outcome must satisfy the new incentive constraints:

$$
\lambda\left[q_{H} \mu_{1} r^{a}+p_{H} R^{a}\left(\mu_{1}\right)\right]-\lambda c \geq \lambda q_{L} \mu_{1} r^{a}+(1-\lambda) q_{L} r^{a}
$$

and

$$
\left\{\begin{array}{l}
q_{H} \mu_{1} r^{a}+p_{H} R^{a}\left(\mu_{1}\right) \geq c \quad(a) \\
c \geq q_{H} r^{a}+p_{H} R^{a}\left(\mu_{1}\right) \quad(b)
\end{array}\right\}
$$

These constraints are obtained by substituting for $R^{a}(1)=\frac{c}{p_{H}}$ into the incentive constraints (7) and (8). Recall that unique implementation requires that constraint (16) be binding when $\Lambda_{q}\left(\lambda \mu_{1}+1-\lambda\right)>1$.

Hence, when constraint (16) is binding the active monitor's optimal contract solves:

$$
\min _{\left\{r^{a}, R^{a}\left(\mu_{1}\right)\right\}}\left\{\lambda\left[q_{H}\left(1-\frac{\mu_{1}}{\mu_{0}}\right) r^{a}+p_{H}\left(1-\frac{1}{\mu_{0}}\right) R^{a}\left(\mu_{1}\right)\right]\right\}+\lambda \psi
$$

subject to constraints (17) and (18).

Solving this problem we obtain the following proposition characterizing the optimal contract that uniquely implements the second best outcome:

Proposition 3 Under the unique implementation requirement,

(a) If either $\mu_{1} \quad \mu^{*}$ or $\mu^{*}<\mu_{1}<\frac{q_{H}+\frac{\lambda}{1-\lambda} q_{L}}{q_{H}-q_{L}}$ and $\Lambda_{q}\left(\lambda \mu_{1}+1-\lambda\right)>1$ then the optimal contract is illiquid and given by

$$
r^{a}=0 \text { and } R^{a}\left(\mu_{1}\right)=R^{a}(1)=\frac{c}{p_{H}},
$$

(b) If $\mu_{1}>\mu^{*}$ and $\Lambda_{q}\left(\lambda \mu_{1}+1-\lambda\right)<1$ the optimal contract is liquid and given by

$$
r^{a}=\frac{c}{\left(q_{H}-q_{L}\right)\left(\lambda \mu_{1}+1-\lambda\right)}, R^{a}\left(\mu_{1}\right)=0 \text { and } R^{a}(1)=\frac{q_{H}}{p_{H}} r^{a},
$$

(c) If $\mu_{1} \geq \frac{q_{H}+\frac{\lambda}{1-\lambda} q_{L}}{q_{H}-q_{L}}$ and $\Lambda_{q}\left(\lambda \mu_{1}+1-\lambda\right)>1$ the optimal contract for the active monitor is liquid and given by:

$$
r^{a *}=\frac{c}{\mu_{1}\left(q_{H}-q_{L}\right)-\frac{1-\lambda}{\lambda} q_{L}} ; R^{a *}\left(\mu_{1}\right)=0 a n d R^{a *}(1)=\frac{c}{p_{H}}
$$


Proof: It only remains to show that the optimal contract characterized in the proposition is indeed the solution to the new constrained optimization problem. As before, constraint (17) must be binding at the optimum, so that

$$
\lambda p_{H} R^{a}\left(\mu_{1}\right)=\lambda\left[c-\left(q_{H}-q_{L}\right) \mu_{1} r^{a}\right]+(1-\lambda) q_{L} r^{a}
$$

Substituting for $\lambda p_{H} R^{a}\left(\mu_{1}\right)$ in the objective function and constraints (18) we then obtain the same objective function as before,

$$
\min _{r^{a}}\left\{r^{a}\left[\lambda q_{H}\left(1-\frac{\mu_{1}}{\mu_{0}}\right)-\lambda\left(1-\frac{1}{\mu_{0}}\right) \mu_{1}\left(q_{H}-q_{L}\right)+(1-\lambda)\left(1-\frac{1}{\mu_{0}}\right) q_{L}\right]\right\}
$$

but a different incentive constraint:

$$
0 \geq\left[q_{H}-\mu_{1}\left(q_{H}-q_{L}\right)+\frac{1-\lambda}{\lambda} q_{L}\right] r^{a} .
$$

Note that constraint (18) (a) is always satisfied. The optimal contract now is liquid if and only if

$$
\mu_{1} \geq \frac{q_{H}+\frac{\lambda}{1-\lambda} q_{L}}{q_{H}-q_{L}}
$$

and given by

$$
r^{a}=\frac{c}{\mu_{1}\left(q_{H}-q_{L}\right)-\frac{1-\lambda}{\lambda} q_{L}} ; R^{a}\left(\mu_{1}\right)=0 \text { and } R^{a}(1)=\frac{c}{p_{H}}
$$

This establishes the proposition. QED

Thus, when

$$
\Lambda_{q}\left(\lambda \mu_{1}+1-\lambda\right)>1
$$

and the principal wants to guarantee unique implementation of the second best outcome, he will have to restrict exit at date $t=1$ more than before if $\widehat{\mu}<\frac{q_{H}+\frac{\lambda}{1-\lambda} q_{L}}{q_{H}-q_{L}}=\left(\Lambda_{q}(1+\right.$ $\left.\left.\frac{\lambda}{1-\lambda} \frac{1}{1-\Lambda_{q}}\right)\right)^{-1}$, which is the case for example if $\mu_{0}$ is sufficiently close to one.

\section{References}


Barry, C., Muscarella, C., Peavy J. and M. Vetsuypens (1990), "The Role of Venture Capital in the Creation of Public Companies: Evidence from the Going Public Process", Journal of Financial Economics, 27:447-471.

Bartlett, J. (1994) Venture Capital: Law, Business Strategies, and Investment Planning, New York, John Wiley

Benveniste, L. and P. Spindt (1989) "How Investment bankers determine the offer price and allocation of new issues", Journal of Financial Economics, 24:343-361.

Berglof, E. (1994), "A Control Theory of Venture Capital Finance", Journal of Law, Economics, and Organization, 10:247-267.

Bhide, A. (1993), "The Hidden Costs of Stock Market Liquidity," Journal of Financial Economics 34, 31-51.

Black, B. and R. Gilson (1998), "Venture Capital and the Structure of Capital Markets: Banks vs Stock Markets", Journal of Financial Economics, 47:243-277.

Bolton, P. and E. von Thadden (1998), "Blocks, Liquidity and Corporate Control", Journal of Finance,53:1-25.

Boot, A. and A. Thakor (1997) "Financial System Architecture", Review of Financial Studies, 10, 693-733

Burkart, M., Gromb, D. and F. Panunzi (1997), "Large Shareholders, Monitoring and the Value of the Firm", Quarterly Journal of Economics, 113:693-728.

Coffee, J. (1991) "Liquidity versus Control: The Institutional Investor as Corporate Monitor", Columbia Law Review, 91:1278-1328.

Diamond, D. and P. Dybvig (1983) "Bank Runs, Deposit Insurance, and Liquidity" Journal of Political Economy, 91:401-419.

Faure-Grimaud, A. and D. Gromb (1999), "Public Trading and Private Incentives", mimeo, LSE and MIT.

Fudenberg, D. and J. Tirole (1990), "Moral Hazard and renegotiation in agency contracts." Econometrica, 56, 755-785

Gompers, P. (1996), "Grandstanding in the Venture Capital Industry", Journal of Financial Economics, 43:133-156.

Gompers, P. and J. Lerner (1999), The Venture Capital Cycle, Cambridge: MIT Press.

Hirschman, A. (1970),Exit, Voice and Loyalty, Harvard University Press.

Holmstrom, B and J. Tirole (1993), "Market Liquidity and Performance Monitoring," Journal of Political Economy 101, 678-709. 
Holmstrom, B and J.Tirole (1997), "Financial Intermediation, Loanable Funds, and the Real Sector", Quarterly Journal of Economics, 112:663-692.

Kahn, Ch. and A. Winton (1998), "Ownership Structure, Liquidity Demand, and Shareholder Monitoring," Journal of Finance, 53:99-129.

Kojima, K. (1997), Japanese Corporate Governance: An International Perspective, Hajime Press, Kobe Japan.

Kyle, A. (1985) "Continuous Auctions and Insider Trading", Econometrica, 53:13151335 .

Lerner, J. (1994) "Venture Capitalists and the Decision to Go Public," Journal of Financial Economics, 35: 293-316.

Lerner, J. (1995) "Venture Capitalists and the Oversight of Private Firms," Journal of Finance, 50:301-318.

Lerner, J. (1999), Venture Capital and Private Equity: A Casebook, New York: John Wiley.

Levin, J. (1995), Structuring Venture Capital, Private Equity, and Entrepreneurial Transactions, Boston, Little-Brown, Chapter 9.

Ma, A. (1991) "Adverse selection in dynamic moral hazard", Quarterly Journal of Economics, 106, 255-75.

Matthews, S. (1995) "Renegotiation of Sales Contracts" Econometrica, 63, 567-90.

Maug, E. (1998), "Large Shareholders as Monitors: is There a Trade-off between Liquidity and Control?", Journal of Finance, 53:65-98.

Mayer, C. (1988) "New Issues in Corporate Finance", European Economic Review, 32, $1167-89$

Myers, S. and N. Majluf (1984), "Corporate Financing and Investment Decisions when Firms Have Information that Investors Do not Have," Journal of Financial Economics 13, 187-221.

Pagano, M. and A. Roell (1998), "The Choice of Stock Ownership Structure: Agency Costs, Monitoring and Liquidity," Quarterly Journal of Economics, 113:187-225.

Rajan, R. (1992) "Insiders and Outsiders: the Choice between Informed and Arm'sLength Debt", Journal of Finance, 47:1367-1400.

Rajan, R. and A. Winton (1995) "Covenants and Collateral as Incentives to Monitor", Journal of Finance, 50: 1113-1146

Rock, K. (1986) "Why New Issues are Underpriced", Journal of Financial Economics, 19:269-281. 
Roe, M. (1990), "Political and legal Restraints on Ownership and Control of Public Companies" Journal of Financial Economics, 27:7-41.

Sahlman, W. (1990) "The Structure and Governance of Venture-Capital Organizations", Journal of Financial Economics, 27:473-521. 